\title{
PARTICIPAÇÃO SOCIAL, VIGILÂNCIA EM SAÚDE DO TRABALHADOR E SERVIÇO PÚBLICO
}

\author{
SOCIAL PARTICIPATION, SURVEILLANCE IN OCCUPATIONAL HEALTH, AND PUBLIC SERVICE
}

PARTICIPACIÓN SOCIAL, VIGILANCIA EN LA SALUD DEL TRABAJADOR Y SERVICIO PÚBLICO

\author{
Kátia Reis de Souza ${ }^{1}$ \\ Renato José Bonfatti ${ }^{2}$ \\ Maria Blandina Marques dos Santos ${ }^{3}$
}

Resumo Este ensaio busca contribuir para a construção de uma modalidade participativa e dialógica de vigilância em saúde para os locais de trabalho, notadamente para o serviço público federal. Nele desenvolve-se uma reflexão com base na revisão da literatura especializada e foco na legislação e na política em vigor no país. Constata-se que as conquistas históricas realizadas no âmbito dos movimentos sociais de trabalhadores propiciam a produção de novas relações entre o Estado e a sociedade, favorecendo o aparecimento de espaços participativos nas instituições públicas. Além disso, evidencia-se a necessidade capital da organização de comissões de saúde do trabalhador por locais de trabalho como forma elementar de implantação da política de vigilância em saúde nos ambientes laborais. Por fim, sob a égide do campo da educação crítica, apresentam-se alguns preceitos do aporte teórico da pedagogia freiriana para que sirvam de base à criação de espaços de fala e escuta no trabalho. Defende-se a ideia de que o diálogo e a participação são os fundamentos educativos de uma perspectiva democrática de vigilância em saúde do trabalhador.

Palavras-chave participação social; vigilância em saúde do trabalhador; serviço público federal; educação dialógica.
Abstract This essay seeks to contribute to the construction of a participatory and dialogical mode of health surveillance for the workplace, notably for the federal public service. A reflection is made in it based on a review of the literature and a focus on the legislation and on the policy in force in the country. The authors find that the historical achievements made in the scope of labor social movements favor the production of new relations between the state and society, favoring the emergence of participatory spaces in public institutions. In addition, it highlights the capital need for organizing occupational health commissions per workplace as an elementary way to implement the health surveillance policy in the work environments. Finally, under the aegis of the critical education field, it presents a few precepts of the theoretical contribution made by Freire's pedagogy to serve as a base for the creation of spaces for discussion at the workplace. The authors defend the idea that dialog and participation are the educational foundations of a democratic perspective of occupational health surveillance.

Keywords social participation; occupational health surveillance; federal public service; dialogical education. 


\section{Introdução}

Os movimentos sociais e os protestos populares iniciados no mês de junho de 2013 no Brasil deixaram marcas e indagações a respeito das estruturas e dos mecanismos de participação em nossas instituições sociais. O Estado brasileiro, como sugere a Constituição Federal (Brasil, 1988), deve ser um dos agentes propulsores das condições propícias ao exercício da democracia. Desse modo, a promoção de ações, a título de exemplaridade, dentro de suas próprias organizações, pode servir de referência ao exercício da democracia cidadã brasileira. É a própria Constituição que prevê diferentes possibilidades para a concretização institucional da participação, o que permite qualificar a democracia brasileira como essencialmente participativa (Pessoa e Santana, 2007). No texto da carta constitucional estabeleceram-se princípios participativos de organização do Estado brasileiro, dos quais se destaca a participação da sociedade civil na deliberação sobre políticas públicas (Avritzer, 2009). Como ilustração, pode-se citar a experiência dos conselhos de saúde, que foram instituídos como importantes canais de participação social no âmbito do próprio Estado. Não obstante, depois de decorridos 25 anos da promulgação da lei constitucional maior, buscam-se, ainda, novas estratégias para ampliação e aperfeiçoamento da democracia e da participação institucional no Brasil (Szwako, 2012; Souto e Paz, 2012).

O Estado é uma organização estruturada com o objetivo de proporcionar a execução de políticas públicas voltadas para os cidadãos. No entanto, são as pessoas, ou melhor, são os funcionários públicos, por meio do seu trabalho, que dão 'vida' a esse sistema. Assim, o Estado como empregador é uma instituição de trabalho, e os funcionários públicos são os trabalhadores. Aqui, há o reconhecimento de que são as pessoas que organizam o contexto institucional e estabelecem relações humanas e sociais no trabalho. Portanto, são os funcionários os agentes portadores de ações para o desenvolvimento de mudanças (Gomes, 2008).

Existem poucos estudos divulgados sobre instituições públicas como espaços de diálogo e participação a respeito da saúde dos próprios funcionários públicos. Também são poucos os relatos de experiências de vigilância participativa nos ambientes de trabalho, embora tenhamos localizado na literatura do campo da saúde coletiva algumas importantes experiências que estão aqui registradas. Portanto, neste ensaio temos como objetivo principal contribuir para a construção de uma modalidade dialógica e participativa de vigilância em saúde para os locais de trabalho, especialmente para o serviço público federal, elegendo, dessa forma, novos caminhos para a ação política pública no campo da vigilância em saúde do trabalhador.

Assim, este ensaio está organizado em seis seções, além da introdução e das considerações finais: na primeira, apresenta-se a fundamentação filosófica 
do conceito de participação com ênfase na perspectiva da teoria política e dos estudos sobre democracia participativa. Na segunda, além de se delinear a experiência participativa seminal do campo da saúde do trabalhador conhecida como 'Modelo Operário Italiano' -, descrevem-se as relações de dominação existentes nos ambientes de trabalho, lançando mão da genealogia teórica da 'física do poder' de Foucault (2003). A terceira seção tem como propósito central descrever e analisar exemplos concretos de grupos de trabalhadores do serviço público federal, especialmente os docentes universitários e os trabalhadores da saúde, no que diz respeito à relação saúde e trabalho. A quarta tem como intento principal apresentar uma breve abordagem histórica da relação entre Estado brasileiro e funcionalismo público, salientando-se os marcos políticos dessa trajetória no que tange, sobretudo, à experiência dos espaços públicos de negociação coletiva. Na sequência, a quinta seção destaca a necessidade premente da efetivação de uma política de vigilância em saúde do trabalhador para os locais de trabalho do serviço público federal, problematizando a legislação vigente no país.

Ao fim, na sexta parte deste ensaio, defende-se a criação de espaços participativos no trabalho, adotando como substrato teórico a pedagogia dialógica de Paulo Freire (1988; 2001 e 2012) e alguns de seus aspectos filosóficos essenciais. Esses aspectos favorecem a liberdade e a criação coletiva como características de modalidades democráticas de vigilância em saúde para os locais de trabalho. Desse modo, não se postulou um único modelo ou procedimento de ação educativa, evitando-se o reducionismo metodológico, conforme preconiza a própria teoria freiriana.

\section{Participação e serviço público}

Sob o ângulo de compreensão das ciências políticas e levando-se em consideração as formas de democracia do mundo ocidental, o termo participação, tomado em seu sentido estrito, significa a contribuição, direta ou indireta das pessoas para uma decisão política (Bobbio, Matteucci e Pasquino, 2004). Ressalta-se que a participação (política) de modo direto, objeto principal de nosso interesse, é concebida como aquela em que as pessoas são consideradas sujeitos (ativos) - portadores de visão de mundo e de valores variados para a tomada de decisão, levando-se em consideração os seus contextos específicos em que elas acontecem. Compartilhamos a assertiva de Bobbio, Matteucci e Pasquino (2004), de acordo com a qual o ideal democrático supõe cidadãos vigilantes aos problemas existentes no âmbito da esfera pública, sendo necessária para tanto a criação de instrumentos organizativos para a institucionalização da participação nos ambientes de trabalho. Com isso afirma-se, como indispensável, construir estruturas e ocasiões 
para a participação, com estímulos e motivação suficientes ao engajamento dos trabalhadores.

A rigor, a ideia de participação, base de compreensão deste ensaio, está relacionada ao conceito de esfera pública - que, segundo Habermas (1997, p. 93), "pode ser descrita como uma rede adequada para a comunicação de conteúdos (...) sendo espaços concretos de público presente que se alimentam de liberdade comunicativa". Para Bauman (2001), devemos reaprender capacidades esquecidas e nos reapropriarmos de ferramentas perdidas da cidadania para repovoar a hoje quase vazia 'ágora' - o lugar do encontro, debate e negociação entre o indivíduo e o bem comum, privado e público. De acordo com esse autor, o espaço público está cada vez mais vazio de questões públicas, deixando de desempenhar sua antiga função de lugar de encontro e diálogo sobre problemas e questões públicas.

Na linhagem dos estudos sobre democracia participativa levados a efeito por Santos (2003), sobressai a ideia de 'valor emancipatório'. Segundo o autor, a ideia de democracia participativa é central a qualquer projeto de emancipação social. No centro dessa proposição está a noção de que a participação deva ser livre de coerção e significativa da expressão de autonomia dos participantes (Buhlungu, 2003; Santos, 2003).

Note-se que, para o campo da teoria política (Cunningham, 2009), os processos de democracia exaltam como tarefa maior a maximização do engajamento ativo dos cidadãos e o fortalecimento das relações de solidariedade. Ainda quanto à perspectiva da filosofia, é relevante a definição de Castoriadis (2002, p. 264) sobre democracia como sendo "o regime em que a esfera pública torna-se verdadeiramente pública - pertencente a todos e efetivamente aberta à participação de todos". Na acepção desse pensador, a democracia é um movimento que, embora se apoie em instituições, é ela própria a autoinstituição da coletividade pela coletividade.

Embora sejam essas condições fundamentais ao exercício da democracia, sabe-se que ainda hoje a cultura de participação no trabalho é baixa ou limitada por motivos diversos. De acordo com Avritzer (2008), o sucesso dos processos participativos está relacionado, diretamente, à maneira como se articulam desenho institucional, organização da sociedade civil (incluindo a dos trabalhadores) e vontade política.

No que tange à democratização do Estado brasileiro, Szwako (2012) afirma que ela permanece como questão central no ideário das lutas por participação política. Para o autor, o sistema de participação institucionalizada, construído principalmente após a Constituição de 1988, foi um avanço significativo na direção da democratização do Estado e na concretização do direito humano à participação. No entanto, alguns elementos negativos da nossa cultura política devem ser identificados e enfrentados, pois tais elementos estão presentes de diferentes modos e com intensidades muito 
variadas nos espaços do serviço público, como o patriarcado, ${ }^{4}$ o patrimonialismo, ${ }^{5}$ o clientelismo 6 e o personalismo, ${ }^{7}$ por exemplo. Todos esses aspectos fazem parte da herança de uma história política de exclusão de direitos políticos e de cerceamento crônico de práticas democráticas de participação (Fleury, 2009).

Nesse sentido, Gomes (2008) chama a atenção para a necessidade da tomada de consciência do servidor quanto ao reconhecimento de seu papel social, que está impregnado de preconceito pela visão social do que é ser servidor público. Vemos e ouvimos cotidianamente muitos depoimentos sobre o serviço público: ouve-se a respeito de improbidades dentro dos órgãos de governo que são difundidas pela mídia, o que contribui para se construir uma visão negativa sobre esse servidor público, colocando-o como único responsável pelo mau funcionamento das instituições públicas e por todas as mazelas e desvios existentes nesse meio. Sem entrar no âmago desse debate, sabe-se que tudo isso pode suscitar excessivas generalizações que rotulam os trabalhadores, levando-os a se tornarem objeto de preconceito, o que fortalece a estereotipia e o estigma social.

Convém lembrar que tal crítica ganha respaldo no âmbito do pensamento econômico a partir da hegemonia do ideário neoliberal, que em sua investida global massiva, principalmente desde os anos 1980, preconiza o 'Estado mínimo' (subordinado ao mercado máximo) como forma de ampliar mercados e conquistar áreas antes restritas ao Estado. É assim que no ano de 1990, por exemplo, o recém-eleito governo brasileiro, o primeiro democraticamente eleito após os anos da ditadura, anuncia a demissão de cerca de 360.000 funcionários públicos como parte de um pacote de medidas que ficou conhecido como Plano Collor (Piccolo, 2010).

Se, por um lado, assistimos a uma desqualificação da atividade do servidor público, por outro não podemos deixar de mencionar a crescente busca pelo emprego nesse setor de trabalho, principalmente pelos jovens, conforme observado em pesquisa realizada por Albrecht e Krawulski (2011). Neste estudo, realizado com 93 alunos de dois cursos preparatórios para ingresso no serviço público, identificaram-se o perfil e os motivos da busca pela carreira no serviço público: a maioria dos participantes é de jovens adultos em início de carreira profissional. O questionário aplicado apresentava a pergunta "Por que você decidiu fazer concursos públicos?" e oferecia como opções as alternativas: qualidade do ambiente de trabalho; flexibilidade de horário; estabilidade no cargo; remuneração; carga de trabalho; carências de alternativas na iniciativa privada; possibilidade de carreira; natureza das tarefas desenvolvidas e outro(s) motivo(s), podendo mais de um ser assinalado. A grande maioria assinalou as alternativas: estabilidade no cargo (89\%) e remuneração (83\%). As demais alternativas também foram assinaladas, embora com menor frequência. 
A despeito do debate sobre a situação econômica e social vigente no país e os preconceitos que sofrem os trabalhadores do serviço público, o fato é que o serviço público ainda é um setor de trabalho atraente, muito concorrido e socialmente valorizado, principalmente por parte das novas gerações.

\section{A vigilância no trabalho sob o enfoque da participação}

Ao nos referirmos ao tema da vigilância em saúde nos locais de trabalho por meio da participação ativa dos trabalhadores, é necessário primeiramente recorrermos ao campo da história das lutas sociais empreendidas, arduamente, por movimentos de trabalhadores. Vamos destacar uma experiência, em particular, que ficou conhecida como 'Modelo Operário Italiano de luta pela saúde' (Oddone et al., 1986), também conhecido como Modelo Operário (MO). Embora tenha ocorrido na Itália nos anos 1970 e em contexto de fábricas, diferentemente dos serviços públicos, podemos apreendê-la no que deixou de exemplo em termos de política participativa no trabalho para a conquista de saúde.

Essa história teve seu auge na década de 1970, quando um grupo de trabalhadores de fábrica aliou-se a um grupo de profissionais de saúde e pesquisadores para, juntos, compreenderem a nocividade dos ambientes de trabalho, na perspectiva de transformá-los. Embora tenha sido uma experiência exemplar e influente (do ponto de vista teórico e metodológico) e um marco histórico importante no campo de lutas por saúde no trabalho, o aspecto que nos interessa destacar aqui é aquele referente à participação dos trabalhadores nos locais de trabalho para a construção de ambientes laborais mais saudáveis. Machado e Netz (2006), em estudo desenvolvido na perspectiva de vigilância em saúde do trabalhador, cuja principal referência adotada foi o MO, destacam que as informações relativas às condições de trabalho e à saúde devam ser validadas com a participação dos trabalhadores a partir de seus locais de trabalho, convalidando a ideia de que para intervir é preciso conhecer. Entre os resultados alcançados, relatam maior visibilidade social aos problemas de saúde enfrentados pelos trabalhadores. Ademais, observam que esse tipo de procedimento torna as negociações coletivas relativas ao trabalho mais qualificadas.

Para Machado (1997), os princípios básicos do chamado modelo operário - não delegar, não monetarizar os riscos e buscar a validação consensual em grupos homogêneos - foram interpretados à luz do movimento sanitário brasileiro e incorporados às experiências de desenvolvimento de ações de vigilância em saúde do trabalhador no interior do Sistema Único de Saúde (SUS) na década de 1980, generalizado pela Lei Orgânica de Saúde, base da reforma sanitária brasileira e do SUS. Segundo Paiva e Vasconcellos (2011), 
o Modelo Operário modificou o conceito corrente segundo o qual a defesa da saúde deveria ficar somente a cargo das instituições oficiais. Ademais, o pressuposto fundamental do modelo é o envolvimento ativo e responsável dos trabalhadores na construção de um novo ambiente de trabalho.

A ideia que queremos destacar é aquela segundo a qual se reconhece que os processos de vigilância em saúde do trabalhador - e a mitigação das causas da nocividade do trabalho - só vão ter sucesso efetivo quando acompanhada das condições objetivas para o exercício real da democracia e da cidadania nos ambientes de trabalho. De maneira que a participação venha a contribuir com as condições propícias para o diálogo e o debate coletivo.

O fato, porém, é que a ideia de vigilância predominante no trabalho como criticava Foucault em Vigiar e punir - é aquela que se relaciona a uma "forte visão disciplinar e de obediência do trabalhador" (Foucault, 2003, p. 143), tornando-se um operador econômico decisivo para o controle dos corpos na produção. A vigilância no trabalho, segundo esse autor, é realizada de forma especializada e hierarquizada, por meio de um controle intenso e ininterrupto que se efetua sobre a atividade, o conhecimento e o comportamento dos trabalhadores. Para Foucault, a vigilância disciplinar é parte integrante do processo de produção e objetiva agir sobre o comportamento das pessoas e em grande parte de forma silenciosa. A rigor, podemos afirmar que ainda é comum a concepção de vigilância no trabalho associada à imagem de um 'poder panóptico', no qual sobressai um olhar superior que tudo vê. Consoante Foucault, as técnicas de vigilância efetuam, ao fim e ao cabo, a 'física do poder'. Nas palavras do autor: "Poder que em aparência é menos corporal por ser mais sabiamente físico" (Foucault, 2003, p. 148).

Sobre essa base de compreensão podemos, complementarmente, citar Kuenzer (2007), que chama a atenção para a existência de uma pedagogia do trabalho, muitas vezes pouco explícita, cujo objetivo é a formação de certo tipo de trabalhador, conveniente aos interesses capitalistas - que, embora apresente certa especificidade, nada mais é do que uma manifestação particular do trabalho capitalista em geral. A autora afirma que esses processos pedagógicos têm por objetivo o disciplinamento da força de trabalho e contribuem para manter a assimetria de poder no trabalho, desfavorável aos trabalhadores. Contrapondo-se a essa lógica, defendemos a ideia de que os processos de vigilância participativa, nos locais de trabalho, devem possibilitar aos próprios trabalhadores serem os agentes da vigilância e das mudanças laborais, pois estariam - pelo exercício democrático do diálogo e do debate sobre a saúde aptos a olharem, a vigiarem e a cuidarem da saúde numa perspectiva coletiva. Importante lembrar também que, sob esse enfoque, cada trabalhador é considerado, em si mesmo, uma unidade de observação no trabalho. Trata-se, portanto, de desenvolvermos instrumentos dialógicos, incorporando a experiência e o saber dos trabalhadores. Além disso, compartilhamos a acepção 
de Bobbio, Matteucci e Pasquino (2004), de acordo com a qual os processos participativos são compreendidos como a base da democracia nas organizações e instituições públicas - e ainda contribuem favoravelmente para a ampliação da democracia política existente na sociedade civil.

Desse modo, lembremos com Machado (2011) que a participação dos trabalhadores é um pressuposto à atividade de vigilância em saúde do trabalhador, pois o saber dos trabalhadores incorpora qualidade técnica ao processo de vigilância. Além disso, produz um efeito de fortalecimento das ações sanitárias por representar força política para transformação das condições de trabalho. Complementarmente, Daldon e Lancman (2013) enfatizam que o papel da vigilância em saúde do trabalhador não é apenas fiscalizador, mas fundamentalmente educativo, sensibilizador e mobilizador de ações transformadoras que precisam ocorrer em parceria com os trabalhadores e em uma abordagem articulada intersetorialmente. Suas ações não se voltam apenas para o trabalhador, mas também para os gestores, que devem ser sensibilizados para a importância de tais mudanças.

Sob o ângulo de compreensão do campo da saúde do trabalhador, há de se colocar em destaque o lado humano do trabalho criando espaços de diálogo e debate. Estudos como o de Silveira e Palassi (2011, p. 213) mostram que a participação no trabalho produz um sentido subjetivo maior: "a necessidade de se desenvolver integralmente como pessoa humana".

Para Alves (2010), existe uma racionalidade redutora das complexidades presentes nas situações de trabalho que comumente se apresentam nas ações da gestão, que não levam em consideração os aspectos de ordem humana no trabalho e acabam produzindo efeitos na saúde dos trabalhadores e trabalhadoras. No estudo de Silveira e Palassi (2011), são analisados casos de funcionários públicos que, ao chegarem ao topo da carreira, apresentam sentimentos de frustração no trabalho, pois alguns seguem padrões obsoletos, estabelecidos há mais de quarenta anos. Agregue-se a isso a dificuldade em lidar com técnicas e ferramentas novas, principalmente ligadas à informática. Os autores chamam a atenção, em particular, para a ausência de estudos que aprofundem os sentidos (subjetivos e objetivos) sobre a participação do servidor público no cotidiano laboral. Sem dúvida, sentimentos como apatia, indiferença e isolamento podem atuar como obstáculo ao processo de integração coletiva, tão importante nos processos de participação no trabalho. Destarte, o estímulo a laços humanos profissionais entre as pessoas no trabalho pode gerar as condições propícias para o fortalecimento dos vínculos de solidariedade e cooperação por meio do fortalecimento do diálogo sobre o próprio trabalho. A cooperação, a solidariedade e o diálogo são valores essenciais à preservação da vida e da saúde nos ambientes laborais. A criação de espaços de participação para o debate sobre a saúde pode ser uma rica experiência de democracia no interior do serviço público. 
Em experiência de planejamento participativo sucedida no âmbito da gestão de um hospital federal (Lima, Faveret e Grabois, 2006), considerou-se que as principais dificuldades foram a pouca participação dos profissionais e a resistência para romper com a estruturação da gestão e do trabalho centrada na lógica da hierarquia de poder intra e intercorporações. Segundo os autores, estas duas dificuldades dão origem à maior parte das demais, pois democratizar uma instituição significa 'mexer' um pouco com as pessoas. Adotar o método participativo, por si só, não garante a sua realização.

\section{Serviço público, condições de trabalho e saúde}

Estudos como o de Gomes (2008) afirmam que as relações que se estabelecem dentro das estão de certa forma mutiladas, impedindo a realização humana no trabalho. Assim, toda e qualquer organizações de trabalho atividade laboral desafia os trabalhadores a uma busca constante de invenções e reinvenções. Segundo Dejours (2004), o trabalho é um elemento central na promoção do desenvolvimento psíquico e da constituição de identidade de homens e mulheres, ao passo que a existência de impedimentos ou constrangimentos organizacionais à realização da criatividade humana no trabalho pode gerar sofrimento mental e adoecimento.

De acordo com Vasconcelos e Faria (2008), a pressão por produtividade crescente, num ambiente extremamente competitivo, exige que o indivíduo esteja sempre pronto para mudar e se adaptar às demandas do mercado. Nesse sentido, os autores apontam para a relação entre a saúde mental do trabalhador e as demandas organizacionais, especialmente as que exigem maior produtividade, agilidade, criatividade e atualização constante.

Dentre os vários segmentos de trabalhadores do funcionalismo público federal, sobressai o caso dos docentes universitários. De fato, as recentes mudanças no trabalho incidiram diretamente sobre a saúde desses trabalhadores. Para Maués (2010), a precarização, a intensificação, o sofrimento e o adoecimento são expressões hoje que permeiam a vida do trabalhador docente. A reforma do Estado brasileiro iniciada na metade dos anos 1990 é um marco referencial para que se entenda o papel que a educação superior passou a desempenhar a partir da última década do século passado e dos primeiros anos do terceiro milênio. De acordo com a autora, o destaque dado a esse nível de ensino não é ao acaso; ele faz parte de um arranjo internacional que indica a importância da educação para o desenvolvimento dos países.

Em estudo realizado por Lima e Lima-Filho (2009) com 189 professores de uma universidade federal, chama a atenção a elevada manifestação de queixas relacionadas à saúde mental. Os sintomas de maior prevalência foram: cansaço mental $(53,9 \%)$, estresse $(52,4 \%)$, ansiedade $(42,9 \%)$, 
esquecimento $(42,9 \%)$, frustração $(37,8 \%)$, nervosismo $(31,1 \%)$, angústia $(29,3 \%)$, insônia $(29,1 \%)$ e depressão $(16,8 \%)$.

Outro importante setor do serviço público a ser mencionado devido ao cenário de problemas relacionados à saúde e à organização do trabalho é o campo da saúde. De acordo com Barbosa-Branco e Albuquerque-Oliveira (2011), profissões diretamente relacionadas aos serviços humanos e atendimento ao público têm sido apontadas como de alto risco para o desenvolvimento de transtornos afetivos e distúrbios relacionados ao estresse. Segundo os autores - que investigaram benefícios de auxílio-doença, concedidos pelo Instituto Nacional do Seguro Social (INSS) aos empregados do ramo de atividade da saúde -, os grupos diagnósticos com maiores prevalências de benefícios foram doenças osteomusculares, lesões e doenças mentais. O ramo de atendimento hospitalar apresentou a maior prevalência em relação a outros setores da saúde.

Em uma experiência participativa no trabalho, sucedida com funcionários de um hospital público, Osório, Machado e Minayo-Gomez (2005) realizaram importantes considerações a respeito da cultura de trabalho em hospitais, que justificam a baixa adesão ao exercício de práticas participativas. Por exemplo, saltam aos olhos considerações como gestões centralizadoras, frágeis representações sindicais e descrença acentuada na influência que os coletivos de trabalho podem exercer sobre a organização de suas próprias atividades, observando-se atitudes predominantemente defensivas ante as exigências da organização do trabalho. De acordo com o estudo, os projetos que conseguem maior adesão à participação são aqueles que apresentam problemas bem definidos a serem enfrentados, com perspectivas imediatas de solução, enquanto as propostas que exigem maior reflexão coletiva se chocam com o cansaço e a descrença, expressos na alegação de 'falta de tempo' para participar. Esses autores destacam ainda que, embora os problemas e obstáculos no cotidiano laboral em hospitais sejam evidentes, é certo que adotar formas coletivas de se analisar e compreender saúde pode propiciar, além da gestão democrática, a ampliação das possibilidades de trabalho coletivo no hospital.

\section{O Estado, o funcionalismo público e a questão da participação: uma breve mirada na história}

Na perspectiva de compreensão da história, é preciso considerar a relação entre Estado e funcionalismo público, que podemos resumir partindo dos anos 1990, quando o Brasil aderiu aos preceitos do denominado 'Consenso de Washington'. Desde então, a questão do funcionalismo público passou a ser considerada um problema fiscal, necessitando de medidas políticas no 
sentido de restringir sua dimensão e seus custos. Simultaneamente, as condições e relações de trabalho apresentaram-se mais precarizadas. Embora sejam ainda escassos, estudos como o de Gomes, Silva e Soria (2012) apontam para problemas evidentes que fragilizam o coletivo de trabalho e de modo consequente levam ao enfraquecimento da participação nos locais de trabalho, tais como o crescimento de formas variáveis de remuneração, a ampliação do quadro de temporários e terceirizados e o distanciamento em relação às organizações sindicais. No tocante aos marcos sobre a relação entre políticas de governo, funcionalismo público e participação, é preciso destacar, já no governo Lula, o documento Gestão pública para um Brasil de todos (Brasil, 2003). De acordo com o texto deste documento, o governo teria como propósito reestruturar o serviço público com base em duas vertentes: fazer frente às demandas sociais e tornar o Estado mais 'eficiente, inclusivo e equitativo'. Em tal perspectiva inclui-se o funcionalismo público como operador da reorganização desejada. Para tanto, são propostas várias medidas que visam fomentar uma política de recursos humanos. A maior novidade, no entanto, foi a instituição da Mesa Nacional de Negociação Permanente (MNNP), a qual pretendeu inaugurar um momento novo das relações de trabalho no serviço público. A Mesa foi lançada em 2003 e estabeleceu uma importante ferramenta de diálogo, institucionalizando uma dimensão inédita: ela "assume a tarefa de repensar a administração pública não contra seus funcionários, mas com eles" (Gomes, Silva e Soria, 2012, p. 173).

Assim, é importante mencionar que o governo federal, em seu balanço das atividades de 2004, nutria uma avaliação positiva desde o segundo ano de funcionamento da Mesa, destacando a instalação das Mesas Setoriais de Negociação Permanente, a partir da criação da MNNP no Serviço Público Federal, como grande avanço na construção de um modelo democrático, participativo e inclusivo de relações do trabalho no setor público brasileiro (Brasil, 2007). No entanto, para Gomes, Silva e Soria (2012), as negociações não avançaram suficientemente, entre outros motivos pela falta de encaminhamento dos compromissos de governo com as reivindicações das entidades sindicais. Consoante Silveira (2003), a negociação coletiva constitui um importante instrumento de melhoria das condições de vida e trabalho, já que nas questões referentes à saúde no trabalho, mesmo na vigência de boas legislações de saúde e segurança, ela pode contribuir com formas de vigilância participativa sintonizada com a realidade específica das condições de cada local de trabalho.

As conquistas históricas realizadas no âmbito dos movimentos sociais favoreceram a construção de novas relações entre o Estado e a sociedade, contribuindo para o aparecimento de espaços inusitados de democracia participativa no Brasil. Quanto à participação social em saúde do trabalhador, é preciso reconhecê-la como um direito constitucional desde 1988. Para 
Hoefel e Severo (2011), trata-se de uma forma de participação que deve considerar os espaços dos sindicatos e centrais sindicais, apesar do enfraquecimento político vivido nas últimas décadas por essas organizações. Segundo as autoras, a consolidação da participação social em saúde do trabalhador exige estratégias que fortaleçam as esferas de 'controle social' do SUS e avancem, simultaneamente, no sentido do aperfeiçoamento desses espaços e na criação e legitimação de novas maneiras de participação.

No que tange à política de saúde do trabalhador do serviço público, Andrade (2009) afirma que o Estado brasileiro vem, desde 2003, tomando iniciativas no sentido de construir sua estrutura. Sob a responsabilidade da Coordenação Geral de Seguridade Social e Benefícios do Servidor (COGSS), foi lançado no final de 2005, por meio do decreto n. 5.961/2006, o Sistema Integrado de Saúde Ocupacional do Servidor Público (Sisosp), para convocar e envolver coletivamente os servidores na construção dessa política. No decorrer do processo e de atividades com os grupos participantes, em 2008 houve uma mudança de nome: de Sisosp para Subsistema Integrado de Atenção à Saúde do Servidor (SIASS), como uma versão pretensamente mais orientada pelos preceitos do campo da saúde do trabalhador.

Embora reconheça-se a importância da política em curso para o funcionalismo público federal, considera-se urgente operar mudanças nos ambientes de trabalho que geram adoecimento, contrapondo-se à visão e à cultura adaptativa do homem ao trabalho que culpabilizam os trabalhadores pelo próprio adoecimento. Assim, é necessário programar ações de vigilância em saúde para modificação dos processos de trabalho e também para promoção da saúde por meio da efetivação das equipes de vigilância e promoção à saúde, conforme previsto no Manual de perícia oficial em saúde, do Ministério do Planejamento, Orçamento e Gestão/SIASS (Brasil, 2010a). Cabe lembrar que o envolvimento e a participação dos trabalhadores no processo de construção de políticas são pressupostos do campo da saúde do trabalhador. Com efeito, é o que possibilita a eficácia e o desenvolvimento e execução das ações.

Ainda sobre a política de saúde do servidor público federal, em 2010 foi instituída pela Secretaria de Recursos Humanos do Ministério do Planejamento, Orçamento e Gestão (MPOG) a portaria normativa n. 3/2010 (Brasil, 2010b), que estabelece orientações básicas sobre a norma operacional de saúde do servidor (NOSS). Esta norma expressa a finalidade de se promoverem ações de vigilância nos ambientes e processos de trabalho no âmbito do serviço público federal, buscando a equidade e a responsabilidade sobre as implicações do trabalho na saúde dos servidores, na perspectiva da promoção da saúde. Tratar-se-ia de uma política participativa, focada na integralidade das ações. Propunha-se, por exemplo, a criação de comissões internas de saúde que valorizassem e incentivassem a "participação dos servidores, enquanto 
protagonistas e detentores de conhecimento do processo de trabalho, na perspectiva de agentes transformadores da realidade" (Brasil, 2010b, p. 5).

\section{As organizações por locais de trabalho}

A respeito desse assunto, a legislação trabalhista determina a constituição das comissões internas de prevenção de acidentes (Cipas) nas empresas, com o objetivo de discutir os problemas relativos à saúde no trabalho. Trata-se de uma comissão paritária, formada nos setores de trabalho, com metade dos membros eleitos pelos trabalhadores e a outra metade indicada pelo empregador. Estudos como os de Bakke e Araújo (2010) reconhecem a Cipa como fonte de informações a respeito de registros de acidentes de trabalho e outros dados sobre saúde, questão que não devemos desconsiderar ao tratarmos da relação entre a saúde e o trabalho. Entretanto, de acordo com Silveira (2003), grande parte do movimento sindical faz crítica ao modelo das Cipas e defende a livre organização dos trabalhadores nos locais de trabalho por meio da constituição de comissões de saúde eleitas diretamente pelos trabalhadores. Portanto, reconhecemos o grande valor dos locais de trabalho para a estruturação de uma política participativa de vigilância em saúde do trabalhador.

Schwartz e Durrive (2007) ressaltam que cada local de trabalho é único. Logo, devemos levar em consideração que os variados espaços de trabalho do serviço público são atravessados por culturas políticas e relações interpessoais diversas, que por sua vez também apresentam efeitos diferenciados na saúde. Portanto, cada tipo de trabalho requer modos de ação próprios, construídos, participativamente, no próprio coletivo de trabalho.

Dois marcos são importantes na história da saúde do trabalhador, referentes à temática das organizações por locais de trabalho. O primeiro foi a $2^{a}$ Conferência Nacional de Saúde do Trabalhador, realizada em 1994, já após a promulgação da lei 8.080, de 1990, que estabelece uma nova política de saúde com a preocupação de se garantirem ações de vigilância e fiscalização nas instituições públicas e privadas. Para tal, propõe a criação de comissões de saúde do trabalhador nos serviços públicos e privados, destacando a exigência de que o serviço público passasse a emitir a comunicação de acidente de trabalho (CAT). Recomenda ainda que a comissão de saúde do servidor público seja amplamente discutida nas bases da categoria em âmbitos federal, estadual e municipal, juntamente com seus sindicatos e representações. Essa comissão deve ser composta exclusivamente por servidores, eleitos por seus pares.

Registre-se que tais recomendações foram reforçadas na $3^{\text {a }}$ Conferência Nacional de Saúde do Trabalhador - segundo marco importante -, realizada em 2005, quando se apontou para a necessidade de participação das 
entidades representativas dos trabalhadores do setor público na elaboração da norma regulamentadora de saúde do trabalhador no serviço público. Andrade (2009) chama a atenção para o fato de que, embora existam recomendações dessas conferências para que a legislação se aplique nas instituições públicas e privadas, não há a obrigatoriedade de que elas sejam efetivadas. Cabe ao Estado a sua normatização - e certamente o empenho dos trabalhadores do serviço público e dos gestores para que as indicações das conferências se tornem realidade.

Ainda no que diz respeito aos preceitos legais, em agosto de 2012 foi instituída a Política Nacional de Saúde do Trabalhador e da Trabalhadora (PNSTT) (Brasil, 2012), cujo texto expressa “o patrimônio reflexivo e de práticas acumulado ao longo das últimas décadas por setores acadêmicos, movimentos de trabalhadores e profissionais que atuam nos serviços" (Gomez, 2013, p. 22). A PNSTT é resultado do movimento coletivo de construção de uma política pública, confirmando assim a importância da participação como estratégia de fortalecimento do interesse comum.

Freitas (2005) lembra que é nos momentos em que o serviço público é administrado por políticas participativas que se abre a possibilidade para incrementar tanto a qualidade do serviço público como a organização dos seus trabalhadores, com o fim de criar condições para fortalecimento de estratégias locais de realização de uma perspectiva coletiva de mudanças. Nessa linha de compreensão, as políticas participativas geram envolvimento dos trabalhadores que estão na 'ponta' do sistema. Trata-se, portanto, de uma construção local e não uma transferência de um órgão central para a 'ponta' do sistema. Tal construção pode ser guiada por um projeto pedagógico da instituição local, consideradas as políticas globais emanadas de órgãos centrais, demandando do poder público as condições necessárias à sua realização (Freitas, 2005).

\section{Criação de espaços para a participação e o diálogo no trabalho}

Sobre esse ponto, cabe ressaltar a importância da criação de espaços de fala e escuta no trabalho, os quais contribuem para ambientes democráticos, em que a palavra circule e provoque descobertas, construindo conhecimento e tecendo sentidos para a vida, assim como preconizado pela perspectiva pedagógica construída por Paulo Freire $(1988,2001)$. No entanto, não se deve ignorar a existência de conflitos e tensões entre os processos educativos de caráter crítico e a estrutura autoritária de organização de trabalho no modo de produção capitalista.

Em Paulo Freire $(1988,2001)$, o sentido do diálogo é essencialmente educativo e político, e tem como principal propósito a formação humana 
para a reflexão e a ação, principalmente em sua dimensão coletiva. Destarte, trata-se de um diálogo vivo e inclusivo, em que todos têm o direito de participar, estabelecendo como princípio a valorização do homem como ser político.

Devemos, por conseguinte, organizar espaços no próprio trabalho, realizando encontros em que seja possível falar e ouvir o outro, pois a vigilância em saúde do trabalhador se realiza, de modo elementar, no cuidado e na atenção sobre a nossa própria saúde e a daqueles que estão próximos, submetidos ao mesmo processo de trabalho. Assim, o diálogo deve acontecer tendo como centro as condições concretas de trabalho. Na linha de Paulo Freire (1988), o diálogo em grupo (círculos de cultura) tem como propósito 'recriar' criticamente o mundo. A rigor, não há professor, há uma coordenação que propicia as condições favoráveis à dinâmica de grupo. A intenção é promover oportunidades para as pessoas poderem pronunciar a própria palavra e construir uma visão própria e autêntica a respeito da sua saúde, expressando as suas condições de trabalho e de vida. Segundo Freire (1988), em diálogo circular constroem-se as possibilidades de mudanças. Nessa proposta, vale convidar especialistas, organizar grupos de leitura e debates a respeito de textos especializados sobre a saúde e o trabalho relacionados ao serviço público.

Trata-se, portanto, de um processo de aprendizagem e criação coletiva, em que o respeito pela visão de mundo do outro é condição para que não haja uma imposição de compreensão entre os participantes. Um aspecto importante e peculiar a esse tipo de trabalho é que as perguntas e os questionamentos devam ser sempre estimulados, para que as respostas se construam por meio de reflexões feitas no interior do próprio grupo, de modo a permitir um processo democrático de debate, no qual todos tenham direito ao uso da palavra. Por certo, conforme afirma Freire (2012), o diálogo é uma das matrizes da qual nasce a própria democracia.

Não é de surpreender que a Organização Internacional do Trabalho (OIT) venha incentivando uma linha de negociação denominada de 'diálogo social', que inclui a negociação coletiva. Para esse organismo internacional, o setor público responde por uma parcela muito significativa do número de empregos em todos os países, sendo considerado um setor-chave no mundo do trabalho. Segundo o documento da OIT, designado de Manual de negociação coletiva e resolução de conflitos no serviço público (Organização Internacional do Trabalho, 2011), o sucesso do diálogo social depende de diversos fatores, como por exemplo o respeito aos direitos fundamentais de liberdade de associação e de negociação coletiva; organizações fortes e independentes de trabalhadores e empregadores, dotadas de capacidade técnica e dos conhecimentos necessários para participar do diálogo social. Desse modo, a troca de informações é o processo mais básico do diálogo social, sendo considerada 
um pressuposto para se promoverem normas internacionais que garantam relações de trabalho mais saudáveis. Deve-se considerar ainda que as pessoas passam parte considerável de suas vidas nos seus locais de trabalho e que esses locais devem ser encarados como espaços privilegiados para a reflexão, o diálogo, a organização e a ação em favor da saúde e da vida.

De acordo com Machado e Porto (2003), o diálogo é uma importante perspectiva para a transformação das práticas sociais e institucionais e de superação das dificuldades para efetivação da integração disciplinar e setorial, tão fundamentais ao sucesso das experiências de vigilância em saúde. Para os autores, é igualmente importante a construção de redes e de ações interinstitucionais de caráter participativo, em torno de problemas concretos de saúde, para a continuidade das ações no âmbito da vigilância em saúde do trabalhador. Tais espaços de organização permitem a construção da democracia, da cidadania e da justiça social em nosso país.

Para D'Acri e colaboradores (2009), os grupos de discussão sobre a relação trabalho e saúde são instrumentos de formação por meio da troca, da experiência e do uso da palavra. Neles deve ser problematizado o quadro de degradação das condições de vida no trabalho por meio do diálogo. Segundo esses autores, a cultura política ativa no mundo do trabalho afasta os trabalhadores da prática de participação e decisão. Portanto, é fundamental que o trabalhador possa fazer uso da palavra e da crítica, pois o silêncio pode levá-lo ao isolamento e sofrimento. Para Freire (2012), o diálogo é um elemento fundamental da relação pedagógica de transformação das pessoas e da vida.

\section{Considerações finais}

Apesar de apresentadas de modo breve, as experiências participativas em cenário do serviço público ocorridas tanto na esfera macrossocial de negociação - entre organizações de trabalhadores e governo - quanto no âmbito microssocial - por meio das experiências de defesa da saúde nos locais de trabalho - podem servir de inspiração a outras. Decerto, concebe-se que processos participativos no trabalho devam ser experimentados e vivenciados, pois a democracia real se constrói por meio da aprendizagem (Freire, 2012). Desse modo, o exercício dos preceitos democráticos é imprescindível para a renovação das ações e da própria teoria política.

No que se refere aos aspectos legais do tema relativo à participação, vigilância e serviço público, o texto constitucional de 1988 e as legislações específicas do campo da saúde do trabalhador devem ser a base legal e política para que se desenvolvam práticas participativas de vigilância. Além disso, não se pode deixar de considerar a convenção 151 da OIT, que estabe- 
lece a negociação coletiva no setor público. Entretanto, ela não se torna obrigatória a partir de um dispositivo legal (Gomes, Silva e Soria, 2012), tornando-se fundamental o empenho das representações dos trabalhadores para fazer valer, também, as normas internacionais do trabalho.

Devemos lembrar, por fim, que a participação social é um eixo central da proposta de reforma sanitária e pode ser considerada como uma vigorosa estratégia de democratização das relações sociais e adensamento da cidadania no Brasil (Fleury, 2009). Por conseguinte, deve-se criar mecanismos participativos inovadores, principalmente no âmbito do local de trabalho. É igualmente essencial compreender que os processos de caráter participativo são capazes de provocar transformações na sociabilidade no trabalho e suscitar transformações nas formas de gestão do aparelho estatal, revitalizando a política cotidiana e ampliando a esfera pública.

Por conseguinte, faz-se mister uma mudança de cultura política no serviço público, com ênfase na valorização da organização do trabalho em equipe e na criação de espaços de diálogo sobre o trabalho e a saúde, estimulando novos fluxos de comunicação e cooperação que sirvam como referências importantes para a vigilância em saúde. Contudo, constata-se, tanto no plano teórico quanto no prático, a necessidade do apoio dos dirigentes e gestores do serviço público como precondição para o estabelecimento da participação dos funcionários no trabalho (Daldon e Lancman, 2013; Fleury, 2009; Gomes, Silva e Soria, 2012).

Como último aspecto importante a ser destacado, ressaltamos a fundamental organização de comissões de saúde do trabalhador por locais de trabalho, conforme preconizado pelo PNSTT e como forma elementar de implantação da vigilância em saúde nos ambientes de trabalho. Nelas, deve ser estimulado o livre debate sobre os problemas que dizem respeito diretamente à saúde individual e coletiva dos trabalhadores, servindo de base de sustentação ao Estado para consolidação da política de saúde do trabalhador também na esfera do serviço público federal, na profícua perspectiva do modelo dialógico de vigilância participativa.

\section{Colaboradores}

Katia Reis de Souza concebeu o tema do estudo, realizou levantamento do material bibliográfico de pesquisa, participou da redação e discussão dos dados. Renato José Bonfatti contribuiu com o levantamento bibliográfico, participou da análise e discussão dos dados e efetuou a revisão final do 
manuscrito. Maria Blandina Marques dos Santos participou da redação, da análise e da aprovação final do manuscrito.

Resumen Este ensayo pretende contribuir a la construcción de un modo participativo y dialógico de vigilancia en la salud en los locales de trabajo, en particular para el servicio público federal. En el mismo se desarrolla una reflexión basada en la revisión de la literatura especializada y se centra en la política y la legislación vigente en el país. Se observa que los logros históricos alcanzados bajo los movimientos sociales de los trabajadores fomentan la producción de nuevas relaciones entre el Estado y la sociedad, lo que favorece la aparición de espacios de participación en las instituciones públicas. Además de ello, se pone de relieve la necesidad esencial de una organización de comisiones de salud del trabajador por locales de trabajo como forma elemental de implantación de la política de vigilancia en la salud en los ambientes laborales. Por fin, en el marco del campo de la educación crítica, se presentan algunos preceptos de la contribución teórica de la pedagogía de Freire para que sirvan como base a la creación de espacios para el diálogo en el trabajo. Se defiende la idea de que el diálogo y la participación son los fundamentos educativos de una perspectiva democrática de vigilancia en la salud del trabajador.

Palabras clave participación social; vigilancia en la salud del trabajador; servicio público federal; educación dialógica.

\section{Notas}

1 Fundação Oswaldo Cruz, Escola Nacional de Saúde Pública Sergio Arouca, Centro de Estudos da Saúde do Trabalhador e Ecologia Humana, Manguinhos, Rio de Janeiro, RJ, Brasil.

Doutora em Saúde Pública pela Escola Nacional de Saúde Pública Sergio Arouca, da Fundação Oswaldo Cruz.

$<$ katreis@ensp.fiocruz.br>

Correspondência: Rua Henrique Fleiuss, 155, apartamento 303, Tijuca, CEP 20521260, Rio de Janeiro, RJ, Brasil.

2 Fundação Oswaldo Cruz, Escola Nacional de Saúde Pública Sergio Arouca, Centro de Estudos da Saúde do Trabalhador e Ecologia Humana, Manguinhos, Rio de Janeiro, RJ, Brasil.

Doutor em Ciências da Engenharia de Produção pela Universidade Federal do Rio de Janeiro.

$<$ renato.bonfatti@gmail.com>

3 Fundação Oswaldo Cruz, Escola Nacional de Saúde Pública Sergio Arouca, Centro de Estudos da Saúde do Trabalhador e Ecologia Humana, Manguinhos, Rio de Janeiro, RJ, Brasil.

Mestre em Saúde Pública e Meio Ambiente pela Escola Nacional de Saúde Pública Sergio Arouca, da Fundação Oswaldo Cruz.

<blandmar@ensp.fiocruz.br> 
4 "Qualquer sistema de organização política, econômica, industrial, financeira, religiosa e social no qual a esmagadora maioria de posições superiores na hierarquia é ocupada por homens" (Moroni, 2012, p. 46).

5 “Conduta política de elites dominantes no exercício de funções públicas de governo, caracterizada pela apropriação do que é público - do Estado, suas instituições e seus recursos - como se fosse patrimônio privado" (Moroni, 2012, p. 46).

6 "Prática baseada na troca de favores e no apadrinhamento, valendo-se de estruturas e serviços públicos para responder ao interesse particular daqueles que exercem a função pública" (Moroni, 2012, p. 46).

7 "Culto às personalidades, com a consequente desvalorização do debate político e a despolitização dos conflitos" (Moroni, 2012, p. 46).

\section{Referências}

ALBRECHT, Pricila A. T.; KRAWULSKI, Edite. Concurseiros e a busca por um emprego estável: reflexões sobre os motivos de ingresso no serviço público. Cadernos de Psicologia Social do Trabalho, São Paulo, v. 14, n. 2, p. 211-226, 2011.

ALVES, Wanderson F. Gestão escolar e o trabalho dos educadores: da estreiteza das políticas à complexidade do trabalho humano. Educação \& Sociedade, Campinas, v. 31, n. 110, p. 17-34, 2010.

ANDRADE, Elsa T. O processo de implementação da política de atenção à saúde do trabalhador em instituições públicas federais: o desafio da integralidade. Dissertação (Mestrado em Saúde Pública) - Escola Nacional de Saúde Pública Sergio Arouca, Fundação Oswaldo Cruz, Rio de Janeiro, 2009.

AVRITZER, Leonardo. Instituições participativas e desenho institucional: algumas considerações sobre a variação da participação no Brasil democrático. Opinião Pública, Campinas, v. 14, n. 1, p. 43-64, 2008.

AVRITZER, Leonardo. Associativismo e participação na saúde: uma análise da questão na região Nordeste do Brasil. In: FLEURY, Sonia; LOBATO, Lenaura V.(Org.). Participação, democracia e saúde. Rio de Janeiro: Cebes, 2009. p. 24-46.

BAKKE, Hanne A.; ARAÚJO, Nelma M. C. Acidentes de trabalho com profissionais de saúde de um hospital universitário. Produção, São Paulo, v. 20, n. 4, p. 669-676, 2010.

BARBOSA-BRANCO, Anadergh; ALBUQUERQUE-OLIVEIRA, Paulo R. Prevalência de incapacidade para o trabalho no setor saúde no Brasil, 2004. Tempus Actas de Saúde Coletiva, Brasília, v. 5, n. 1, p. 1-16, 2011.

BAUMAN, Zygmunt. Modernidade líquida. Rio de Janeiro: Jorge Zahar, 2001.

BOBBIO, Norberto; MATTEUCCI, Nicola; PASQUINO, Gianfranco. Dicionário de política. Brasília: Ed. UnB, 2004.

BRASIL. Constituição da República Federativa do Brasil. Brasília, DF, 5 out. 1988. Disponível em: $<$ www.planalto.gov.br/ccivil_03/constituicao/ constituicao.htm>. Acesso em: 28 nov. 2013.

BRASIL. Ministério do Planejamento. Secretaria de Gestão. Gestão pública para um 
Brasil de todos: um plano de gestão para o governo Lula. Brasília: Ministério do Planejamento, Orçamento e Gestão, 2003. Disponível em: <www.economia.esalq.usp.br/ intranet/uploadfiles/3823.pdf >. Acesso em: 8 mar. 2015.

BRASIL. Ministério do Planejamento. Governo investe em politicas de valorização do servidor. 2007. Disponível em: <www. planejamento.gov.br/noticia.asp? $\mathrm{p}=$ not $\& \operatorname{cod}=$ $1753 \&$ cat $=26 \&$ sec $=11>$. Acesso em: 28 out. 2012.

BRASIL. Ministério do Planejamento, Orçamento e Gestão. Subsistema Integrado de Atenção à Saúde do Servidor (SIASS). $M a$ nual de perícia oficial em saúde. Brasília: Ministério do Planejamento, Orçamento e Gestão, 2010a. Disponível em: <www.ufal.edu. br/servidor/desenvolvimento/qualidade-devida/opt-appfiles-siapenet-banner-manual. pdf>. Acesso em: 8 mar. 2015.

BRASIL. Ministério do Planejamento, Orçamento e Gestão. Portaria normativa n. 3, de 7 maio de 2010. Estabelece orientações básicas sobre a norma operacional de saúde do servidor. Diário Oficial da União, Poder Executivo, Brasília, 10 maio 2010b. Disponível em: $<$ www010.dataprev.gov.br/sislex/paginas/ 61/MP/2010/3_1.htm >. Acesso em: 28 nov. 2013.

BRASIL. Portaria n. 1.823, de 23 de agosto de 2012. Institui a Política Nacional de Saúde do Trabalhador e da Trabalhadora. Diário Oficial da União, Poder Executivo, Brasília, 23 ago. 2012. Disponível em: <http://bvsms.saude.gov.br/bvs/saudelegis/ gm/2012/prt1823_23_08_2012.html>. Acesso em: 28 nov. 2013.

BUHLUNGU, Sakhela. O reinventar da democracia participativa na África do Sul. In: SANTOS, Boaventura S. Democratizar a democracia: os caminhos da democracia participativa. Rio de Janeiro: Civilização Brasileira, 2003. p. 133-165.

CASTORIADIS, Cornelius. As encruzilhadas do labirinto: a ascensão da insignificância. São Paulo: Paz e Terra, 2002.
CUNNINGHAM, Frank. Teorias da democracia. Porto Alegre: Artmed, 2009.

D'ACRI, Vanda et al. Formação de trabalhadores e pesquisa na construção do movimento de ação solidária de luta pela saúde: o caso da Associação Brasileira de Expostos ao Amianto do Rio de Janeiro (Abrea/RJ). Saúde \& Sociedade, Campinas, v. 18, n. 1, p. 154-163, 2009.

DALDON, Maria T. B.; LANCMAN, Selma. Vigilância em saúde do trabalhador: rumos e incertezas. Revista Brasileira de Saúde Ocupacional, São Paulo, v. 38, n. 127, p. 92106, 2013.

DEJOURS, Christophe. O trabalho como enigma. In: LANCMAN, Selma; SZNELWAR, Laerte. (Org.). Christophe Dejours: da psicopatologia à psicodinâmica do trabalho. Rio de Janeiro, Brasília: Editora Fiocruz; Editora Paralelo 15, 2004. p. 127-140.

FLEURY, Sonia. Socialismo e democracia: o lugar do sujeito. In: FLEURY, Sonia; LOBATO, Lenaura V. Participação, democracia e saúde. Rio de Janeiro: Cebes, 2009. p. 24-46.

FOUCAULT, Michel. Vigiar e punir: nascimento da prisão. Petrópolis: Vozes, 2003.

FREIRE, Paulo. Pedagogia do oprimido. Rio de Janeiro: Paz e Terra, 1988.

FREIRE, Paulo. Pedagogia da autonomia: saberes necessários à prática educativa. São Paulo: Paz e Terra, 2001.

FREIRE, Paulo. Educação e atualidade brasileira. São Paulo: Cortez, 2012.

FREITAS, Luiz C. Qualidade negociada: avaliação e contrarregulação na escola pública. Educação \& Sociedade, Campinas, v. 26, n. 92, p. 911-933, 2005.

GOMES, Darcilene C.; SILVA, Leonardo B.; SORIA, Sidartha. Condições e relações de trabalho no serviço público: o caso do governo Lula. Revista de Sociologia e Política, Curitiba, v. 20, n. 42, p. 167-181, 2012. 
GOMES, Nanci F. A subjetividade do servidor público constituída na relação com o Estado e a sociedade. Psicologia para América Latina, São Paulo, n. 15, 2008. Disponível em: <www.psicolatina.org/15/ subjetividade.html $>$. Acesso em: 8 mar. 2015.

GOMEZ, Carlos M. Avanços e entraves na implementação da Política Nacional de Saúde do Trabalhador. Revista Brasileira de Saúde Ocupacional, São Paulo, v. 38, n. 127, p. 21-25, 2013.

HABERMAS, Jürgen. Direito e democracia: entre facticidade e validade. v. 2. Rio de Janeiro: Tempo Brasileiro, 1997.

HOEFEL, Maria G.; SEVERO, Denise O. Participação social em saúde do trabalhador: avanços, desafios e perspectivas contemporâneas. Tempus Actas de Saúde Coletiva, Brasília, v. 5, p. 119-138, 2011.

KUENZER, Acacia Z. Da dualidade assumida à dualidade negada: o discurso da flexibilização justifica a inclusão excludente. Educação \& Sociedade, Campinas, v. 28, n. 100, p. 1.153-1.178, 2007.

LIMA, Juliano C.; FAVERET, Ana C.; GRABOIS, Victor. Planejamento participativo em organizações de saúde: o caso do Hospital Geral de Bonsucesso, Rio de Janeiro, Brasil. Cadernos de Saúde Pública, Rio de Janeiro, v. 22, n. 3, p. 631-641, 2006.

LIMA, Maria F. E. M.; LIMA-FILHO, Dario O. Condições de trabalho e saúde do/a professor/a universitário/a. Ciências e Cognição, Rio de Janeiro, v. 14, n. 3, p. 62-82, 2009.

MACHADO, Jorge M. H. Processo de vigilância em saúde do trabalhador. Cadernos de Saúde Pública, Rio de Janeiro, v. 13, supl. 2, p. 533-545, 1997.

MACHADO, Jorge M. H. Perspectivas e pressupostos da vigilância participativa no Brasil. In: GOMEZ, Carlos M.; MACHADO, Jorge M. H.; PENA, Paulo G. L. Saúde do trabalhador na sociedade brasileira contem- porânea. Rio de Janeiro: Editora Fiocruz, 2011. p. 67-86.

MACHADO, Jorge M. H.; PORTO, Marcelo F. S. Promoção da saúde e intersetorialidade: a experiência da vigilância em saúde do trabalhador na construção de redes. Epidemiologia e Serviços de Saúde, Brasília, v. 12, n. 3, p. 121-130, 2003.

MACHADO, Mauro S.; NETZ, Jacéia A. Vigilância da saúde do trabalhador no Sindicato dos Bancários de Porto Alegre: a operação de olho na saúde. Boletim da Saúde, Porto Alegre, v. 20, n. 1, p. 187-191, 2006.

MAUÉS, Olgaíses. A reconfiguração do trabalho docente na educação superior. Educar em Revista, Curitiba, n. esp. 1, p. 141-160, 2010.

MORONI, José A. Agendas para a participação. In: SOUTO, Anna L. S.; PAZ, Rosangela D. O. Novas lentes sobre a participação: utopias, agendas e desafios. São Paulo: Instituto Pólis, 2012. Disponível em: <www. polis.org.br/uploads/1585/1585.pdf $>$. Acesso em 15 ago. 2013.

ODDONE, Ivar et al. Ambiente de trabalho: a luta dos trabalhadores pela saúde. São Paulo: Hucitec, 1986.

ORGANIZAÇÃO INTERNACIONAL DO TRABALHO (OIT). Departamento de Atividades Setoriais. Manual de negociação coletiva e resolução de conflitos no serviço público. Genebra: OIT, 2011. Disponível em: <www. oitbrasil.org.br/sites/default/files/topic/ gender/pub/manual \%20de $\% 20$ negociacao $\% 20$ coletiva $\% 20$ portugues_858.pdf $>$. Acesso em: 5 out. 2012.

OSORIO, Claudia; MACHADO, Jorge M. H.; MINAYO-GOMEZ, Carlos. Proposição de um método de análise coletiva dos acidentes de trabalho no hospital. Cadernos de Saúde Pública, Rio de Janeiro, v. 21, n. 2, p. 517-524, 2005.

PAIVA, Maria J.; VASCONCELLOS, Luís C. F. Modelo Operário Italiano: o surgimento 
do campo da saúde do trabalhador. In: VASCONCELLOS, Luís Carlos Fadel; OLIVEIRA, Maria Helena. Saúde, trabalho e direito: uma trajetória crítica e a crítica de uma trajetória. Rio de Janeiro: Educam, 2011. p. 357- 400.

PESSOA, Izabel L.; SANTANA, Maria G. Como pensar a participação social no marco da Constituição Federal de 1988: uma reflexão a partir da experiência do Conselho Nacional dos Direitos dos Idosos. Ser Social, Brasília, n. 20, p. 145-167, 2007.

PICCOLO, Monica. A lenta construção do projeto privatista: a política econômica brasileira entre 1964-1974. Outros Tempos, v. 7, n. 10, Maranhão, p. 37-58, 2010.

SANTOS, Boaventura S. Democratizar a democracia: os caminhos da democracia participativa. Rio de Janeiro: Civilização Brasileira, 2003.

SCHWARTZ, Yves; DURRIVE, Louis. Trabalho e ergologia: conversas sobre a atividade humana. Niterói: EdUFF, 2007.

SILVEIRA, Andréa M. Participação dos trabalhadores na redução e eliminação da nocividade do trabalho. In: MENDES, René (Org.). Patologia do trabalho. São Paulo: Ateneu, 2003. p. 1.817-1.832.
SILVEIRA, Rogério Z.; PALASSI, Márcia P. A vida na fazenda: sentidos subjetivos do servidor fazendário ante a participação no trabalho. RAM - Revista de Administração Mackenzie, São Paulo, v. 12, n. 6, p. 192 223, 2011.

SOUTO, Anna L. S.; PAZ, Rosangela D. O. Novas lentes sobre a participação: utopias, agendas e desafios. São Paulo: Instituto Pólis, 2012. Disponível em: <www.polis. org.br/uploads/1585/1585.pdf $>$. Acesso em: 28 nov. 2013.

SZWAKO, José. Participar vale a pena, mas...: a democracia participativa brasileira vista pelas lentes da utopia. In: SOUTO, Anna L. S.; PAZ, Rosangela D. O. Novas lentes sobre a participação: utopias, agendas e desafios. São Paulo: Instituto Pólis, 2012. Disponível em: <www.polis.org.br/uploads/ 1585/1585.pdf>. Acesso em: 28 nov. 2013.

VASCONCELOS, Amanda; FARIA, José H. Saúde mental no trabalho: contradições e limites. Psicologia \& Sociedade, Belo Horizonte, v. 20, n. 3, p. 453-464, 2008.

Recebido em 06/12/2013

Aprovado em 28/08/2014 